\title{
Biosynthetic and regulatory elements involved in the production of the siderophore vanchrobactin in Vibrio anguillarum
}

\author{
Miguel Balado, Carlos R. Osorio and Manuel L. Lemos
}

Correspondence

Manuel L. Lemos

mlemos@usc.es

Received 9 January 2008

Revised 8 February 2008

Accepted 11 February 2008
Department of Microbiology and Parasitology, Institute of Aquaculture and Faculty of Biology,
University of Santiago de Compostela, Campus Sur, Santiago de Compostela 15782, Spain

Some Vibrio anguillarum strains produce a catechol-type siderophore named vanchrobactin, whose biosynthetic pathway has not been completely elucidated. In addition to the previously described genes $v a b A$, vabC, vabB, vabE, vabF, vabS and $v a b H$, in the present study we have identified the genes encoding a DAHP (3-deoxy-D-arabino-heptulosonate-7-phosphate) synthetase (vabG), a phosphopantheteinyl transferase (vabD), a LysR-family transcriptional regulator $(v a b R)$ and a putative siderophore receptor $(f v t A)$. A deletion affecting vabG or vabD greatly reduced growth under iron-limiting conditions, whereas deletion of vabR did not have significant effects. Vanchrobactin production was abolished in the vabD mutant, whereas the $v a b G$ mutant retained a residual vanchrobactin production ability. Reverse transcriptase-mediated PCR indicated that this 11-gene cluster is organized into six iron-regulated transcriptional units. Transcriptional lacZ fusions demonstrated that the ferric uptake regulator (Fur) protein is the main iron-responsive regulator of these genes. Interestingly, the vabG gene was strongly iron-repressed, but Fur was not essential for this repression. In addition, the maximal expression from the $v a b G$ promoter was achieved only in the presence of an intact copy of $v a b R$. Analysis of the $\beta$-galactosidase activities of a $f v t A$ : : lac $Z$ fusion in a vabB mutant and in the presence of added vanchrobactin suggested that a ferric-vanchrobactin-dependent activator plays a positive regulatory role in transcription of the $f v t A-v a b D$ operon. This possibility is reinforced by the presence of a predicted AraC box upstream of $f v t A$. We propose that vanchrobactin biosynthesis is subjected to a complex regulatory circuitry aimed at adjusting vanchrobactin production for the maintenance of iron homeostasis in $V$. anguillarum.

\section{INTRODUCTION}

Iron is an essential nutrient for most bacteria, acting as a cofactor of many enzymes with redox activity. Most of the iron in biological systems is chelated by high-affinity ironbinding proteins, and thus bacterial pathogens have developed efficient mechanisms to obtain iron from host tissues (Ratledge \& Dover, 2000). One of the main strategies is the synthesis of siderophores, high-affinity iron chelators that are released into the extracellular environment, where they complex iron and deliver it to the bacterial cell (Crosa, 1989; Wandersman \& Delepelaire,

Abbreviations: DAHP, 3-deoxy-D-arabino-heptulosonate-7-phosphate; DHBA, 2,3-dihydroxybenzoic acid; EDDA, ethylenediamine-di-(o-hydroxyphenyl acetic acid); Fur, ferric uptake regulator; FURTA, Fur titration assay; LTTR, LysR-type transcriptional regulator; NRPS, non-ribosomal peptide synthetase; PPTase, phosphopantetheinyl transferase.

The GenBank/EMBL/DDBJ accession number for the sequence of $V$. anguillarum is AM168450.

A supplementary table showing the oligonucleotides used in this study is available with the online version of this paper.
2004). Many siderophores are small peptides synthesized by non-ribosomal peptide synthetases (NRPSs), which are multimodular enzymes that produce a peptide without an RNA template (Crosa \& Walsh, 2002; Schwarzer et al., 2003). Other bacterial siderophores of non-polypeptidic nature are synthesized via NRPS-independent pathways (Challis, 2005).

Vibrio anguillarum is the causative agent of vibriosis, a generally fatal haemorrhagic septicaemic disease in a variety of marine animals (Toranzo \& Barja, 1990). It is known that siderophore-mediated iron-acquisition systems play an important role in the pathogenicity of $V$. anguillarum for fish (Di Lorenzo et al., 2003; Wolf \& Crosa, 1986). Currently, two clearly different siderophoremediated systems are known in $V$. anguillarum. Strains that harbour the $65 \mathrm{~kb}$ pJM1 or pJM1-like plasmids produce the siderophore anguibactin (Stork et al., 2002), although its synthesis also requires chromosomal genes (Alice et al., 2005; Chen et al., 1994). Strains that lack pJM1-like plasmids produce a different catecholate siderophore (Conchas et al., 1991; Lemos et al., 1988), named vanchro- 
bactin. Vancrobactin is assembled from the precursors 2,3dihydroxybenzoic acid (DHBA), serine and arginine (Soengas et al., 2006), following an NRPS-based mechanism encoded by chromosomal genes (Fig. 1). VabE, VabB and VabF are three NRPSs that have been demonstrated to be essential for vanchrobactin biosynthesis (Balado et al., 2006). Phosphopantetheinyl transferases (PPTases) are required for the NRPS to be functional, since they catalyse the essential posttranslational activation of carrier proteins (Crosa \& Walsh, 2002). To date, no candidate PPTase genes have been described in vanchrobactin-producing $V$. anguillarum strains.

DHBA, one of the vanchrobactin components, is synthesized from chorismate (an aromatic amino acid intermediate). One of the steps in the biochemical pathway that leads to chorismate is catalysed by the DAHP synthase, responsible for the production of 3-deoxy-D-arabinoheptulosonate-7-phosphate (DAHP). This enzyme represents a key regulatory point in aromatic amino acid biosynthesis (Kloosterman et al., 2003), and in a few species homologues of DAHP synthase genes have been found linked to siderophore biosynthesis gene clusters (Di Lorenzo et al., 2003; Osorio et al., 2006), although no functional studies have been conducted.

The expression of genes involved in siderophore biosynthesis and uptake must be strictly regulated (Touati, 2000). The ferric uptake regulator (Fur) protein has been described as a major transcriptional regulator that represses the expression of many of the genes involved in iron acquisition (Braun et al., 1998; Braun \& Killmann, 1999; Escolar et al., 1999). However, in some organisms, Fur can act indirectly as a positive regulator in controlling gene expression, for instance through the action of the small RNA RyhB (Masse \& Gottesman, 2002). Genes involved in the biosynthesis of siderophores can also be subjected to transcriptional activation. There is increasing evidence that AraC-family activators are necessary for maximal expression of the respective siderophore biosynthetic and transport genes, and that these regulators require the cognate siderophore as a cofactor (Anderson \& Armstrong, 2004; Brickman et al., 2001; Fetherston et al., 1996; Michel
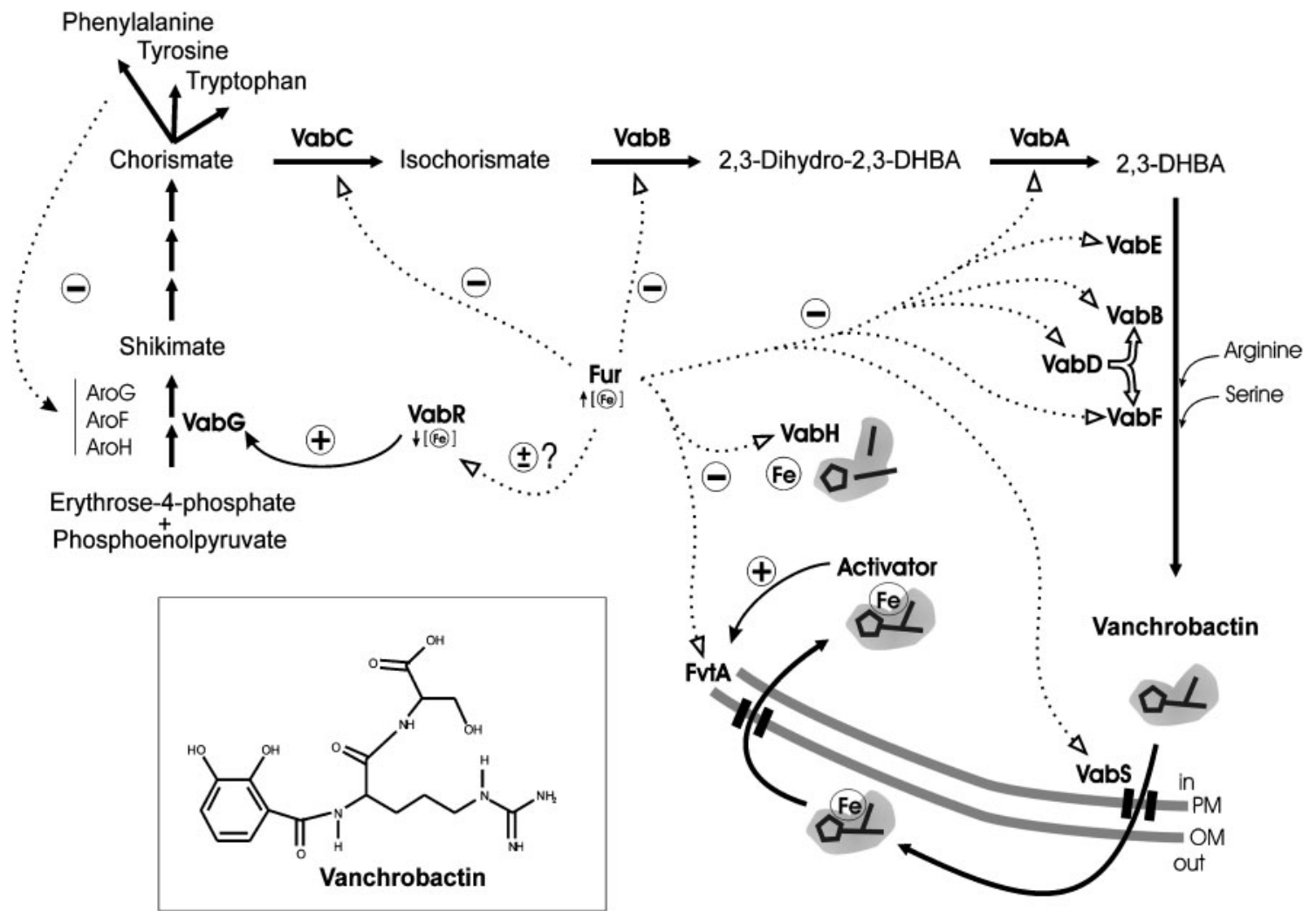

Fig. 1. A proposed scheme for vanchrobactin biosynthesis and regulation. A circled plus symbol denotes activation and a circled minus symbol indicates repression. The Fur repressor protein, under conditions of high iron, represses transcription of the genes encoding VabCBAEDFHS and FvtA proteins (dashed lines ending in empty arrowheads). A dashed line ending in a filled arrowhead denotes negative regulation mediated by aromatic amino acids of genes encoding AroGFH proteins. The empty arrow arising from VabD shows the activation of the VabF peptide carrier protein (PCP) domains and VabB aryl carrier protein (ArCP) domain by VabD. 
et al., 2005; Pelludat et al., 1998). Similarly, LysR-type transcriptional regulators (LTTRs) activate the expression of genes involved in a wide range of cellular processes, such as amino acid biosynthesis (Panina et al., 2001), virulence (Watnick et al., 1998) and iron uptake (Vasil et al., 1998). Most LTTRs are encoded by genes that are transcribed divergently from their target genes, and operate together with a small ligand that acts as a coinducer (Schell, 1993).

In a previous work, we characterized a cluster of seven genes involved in vanchrobactin biosynthesis and utilization, and proposed a preliminary biosynthetic model for vanchrobactin (Balado et al., 2006). These genes included those responsible for the synthesis of DHBA from chorismate $(v a b A B C)$, as well as the NRPSs involved in activation of DHBA ( $v a b E$ ), and the final assembly of DHBA, serine and arginine ( $v a b F)$ to make vanchrobactin. Other genes putatively involved in siderophore export $(v a b S)$ and utilization $(v a b H)$ were also described as part of the cluster (Balado et al., 2006). In the present study, we identified and characterized additional genetic determinants involved in the vanchrobactin biosynthetic pathway, and showed that vanchrobactin biosynthesis is subjected to a complex regulatory circuitry.

\section{METHODS}

Bacterial strains, plasmids and media. The strains and plasmids used, as well as those derived from this study, are listed in Table 1. V. anguillarum strains were routinely grown at $25{ }^{\circ} \mathrm{C}$ in Tryptic Soy Agar and Broth (Difco) supplemented with $1 \% \mathrm{NaCl}$ (TSA-1 and TSB-1, respectively). Escherichia coli strains were routinely grown at $37{ }^{\circ} \mathrm{C}$ in Luria-Bertani (LB) medium (Pronadisa) supplemented with the appropriate antibiotics. All strains were stored frozen at $-80{ }^{\circ} \mathrm{C}$ in $\mathrm{LB}$ broth with $20 \%$ (v/v) glycerol. Ampicillin sodium salt and kanamycin (Sigma-Aldrich) stock solutions in ultrapure water (100 and $50 \mathrm{mg}$ $\mathrm{ml}^{-1}$, respectively) were filter-sterilized and stored at $-20{ }^{\circ} \mathrm{C}$.

DNA manipulations. Standard DNA manipulations were carried out as described by Sambrook \& Russell (2001). Total genomic DNA from $V$. anguillarum was purified with the Easy-DNA kit (Invitrogen). Plasmid DNA purification and extraction of DNA from agarose gels were carried out using kits from Qiagen. DNA-probe labelling and Southern blot analyses were performed with the ECL DNA Labelling and Detection System (Amersham Biosciences). PCR reactions were carried out in a TGradient Thermal Cycler (Biometra), with Taq polymerase (BioTaq, Bioline). For inverse PCR, chromosomal DNA was digested with a single restriction enzyme, selfligated and used as template in a PCR reaction with the Expand Long Template PCR System (Roche Diagnostics). The most relevant oligonucleotides used in this study are listed in Supplementary Table S1.

Table 1. Bacterial strains and plasmids used in this study

Resistance phenotypes: $\mathrm{Amp}^{\mathrm{R}}$, ampicillin; $\mathrm{Gen}^{\mathrm{R}}$, gentamycin; $\mathrm{Neo}^{\mathrm{R}}$, neomycin; $\mathrm{Sm}^{\mathrm{R}}$, streptomycin; $\mathrm{Tp}^{\mathrm{R}}$, trimethoprim.

\begin{tabular}{|c|c|c|}
\hline Plasmid or strain & Relevant characteristic(s) & Reference or source \\
\hline \multicolumn{3}{|l|}{ Plasmids } \\
\hline pGEMT-Easy & PCR cloning vector, $\mathrm{Amp}^{\mathrm{R}}$ & Promega \\
\hline pWKS30 & Low-copy cloning vector, $\mathrm{Amp}^{\mathrm{R}}$ & Wang \& Kushner (1991) \\
\hline pT7-7 & Cloning vector, $\mathrm{Amp}^{\mathrm{R}}$ & Tabor \& Richardson (1985) \\
\hline pHRP309 & Low-copy-number reporter plasmid, Gen ${ }^{\mathrm{R}}$ & Parales \& Harwood (1993) \\
\hline pMB11 & pHRP309 fvtA: : lacZ fusion & This study \\
\hline pMB12 & pHRP309 vabH: : lacZ fusion & This study \\
\hline pMB19 & pHRP309 vabA: : lacZ fusion & This study \\
\hline pMB20 & pHRP309 vabC: : lacZ fusion & This study \\
\hline pMB33 & pHRP309 vabG: : lacZ fusion & This study \\
\hline pMB34 & pHRP309 vabR: : lacZ fusion & This study \\
\hline SuperCos 1 & Cosmid vector, $\mathrm{Amp}^{\mathrm{R}}$, Neo ${ }^{\mathrm{R}}$ & Stratagene \\
\hline \multicolumn{3}{|c|}{ V. anguillarum strains } \\
\hline RV22 & Wild-type serotype $\mathrm{O} 2$ strain isolated from diseased turbot (Spain) & Lemos et al. (1988) \\
\hline 775 met11 & Serotype O1 strain defective in Fur protein & Tolmasky et al. (1994) \\
\hline MB11 & RV22 $v a b B$ defective mutant & Balado et al. (2006) \\
\hline MB14 & RV22 vabF defective mutant & Balado et al. (2006) \\
\hline MB53 & RV22 vabR defective mutant & This study \\
\hline MB54 & RV22 vabG defective mutant & This study \\
\hline MB67 & RV22 vabD defective mutant & This study \\
\hline \multicolumn{3}{|l|}{ E. coli strains } \\
\hline $\mathrm{DH} 5 \alpha$ & 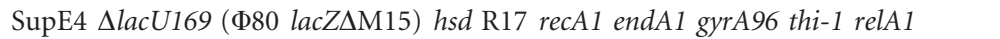 & Laboratory stock \\
\hline S17-1 $\lambda$ pir & $\mathrm{Tp}^{\mathrm{R}} \mathrm{Sm}^{\mathrm{R}}$ recA, thi, pro, hsdR-M+RP4:2-Tc:: Mu-Km:: Tn 7 ppir & Herrero et al. (1990) \\
\hline XL1-Blue MR & $\Delta(m c r A) 183 \Delta(m c r C B-h s d S m r-m r r) 173$ endA1 supE44 thi-1 recA1 gyrA96 relA1 lac & Stratagene \\
\hline H1717 & $\begin{array}{l}\text { araD139 rpsL150 } \Delta(\text { argF-lac) relA1 U169 flbB5301 deoC1 ptsF25 rbsR aroB } \\
\text { fhuF:: } \lambda \text { placMu }\end{array}$ & Hantke (1987) \\
\hline
\end{tabular}


DNA sequencing and bioinformatics tools. DNA sequences were determined with the dideoxy chain-termination method on either plasmid or PCR products using a GenomeLab DTCS Quick Start kit with a CEQ 8000 DNA Sequencer (Beckman Coulter). Sequences were examined and assembled using BioEdit version 7.0.4.1 (Hall, 1999). The European Bioinformatics Institute (EBI) and the NCBI services were used to consult the DNA and protein sequence databases with the FASTA3 and BLAST algorithms. The protein families database of alignments and HMMs (Pfam) of the Sanger Institute was utilized to predict the protein domain organization (Bateman et al., 2004). The Virtual Footprint Promoter Matches from the online database PRODORIC Release 8.1 (http://prodoric.tu-bs.de/) was used to identify putative regulatory operators. MFOLD (3.1.2) (http:// bioweb.pasteur.fr/seqanal/interfaces/mfold-simple.html) was used for RNA secondary structure prediction.

Construction of a V. anguillarum RV22 cosmid library. For construction of a cosmid library, genomic DNA from $V$. anguillarum RV22 was partially digested with the restriction enzyme Sau3AI and ligated into the BamHI site of the SuperCos1 cosmid vector (Stratagene). Recombinant cosmids were packaged in vitro and transduced into E. coli XL1-blue MR (Stratagene). The cosmid library was screened by performing colony PCR on pools of recombinant clones using primers targeted to genes located at the $5^{\prime}$ and $3^{\prime}$ ends of the previously described partial vanchrobactin gene cluster (Balado et al., 2006), and two cosmids, cosMB167 and cosMB69, were isolated. Cosmid DNA was purified using the QIAfilter Plasmid Midi Kit (Qiagen) and used for DNA sequencing.

Construction of vabG, vabD and vabR deletions by allelic exchange. Gene deletions in $V$. anguillarum RV22 were constructed by allelic exchange as previously described (Mouriño et al., 2004). This process led to the obtention of $V$. anguillarum MB53 ( $\Delta v a b R)$, MB67 $(\Delta v a b D)$ and MB54 $(\Delta v a b G)$ mutant strains. Deletion of the parental gene was verified in all cases by Southern blot hybridization. DNA sequencing of the region involved in the deletion was carried out to ensure that all constructs were in-frame.

Growth under iron-limited conditions and test of siderophore production. To test the ability of $V$. anguillarum defective mutants to grow under iron-limited conditions, overnight cultures in LB of the parental and mutant strains were adjusted to $\mathrm{OD}_{600} 0.5$ and diluted $1: 15$ in CM9 minimal medium (Lemos et al., 1988) containing the iron chelator ethylenediamine-di-(o-hydroxyphenyl acetic acid) (EDDA) at $5 \mu \mathrm{M}$. Cultures were incubated at $25^{\circ} \mathrm{C}$ with shaking at 150 r.p.m., and growth $\left(\mathrm{OD}_{600}\right)$ and siderophore production were measured after $22 \mathrm{~h}$ incubation. Siderophore production was measured using the chrome azurol-S (CAS) liquid assay (Schwyn \& Neilands, 1987), which detects the presence of ironchelating siderophore molecules. In addition, the Arnow test (Arnow, 1937), which specifically detects the presence of 2,3-dihydroxybenzoic acid (DHBA), was used for the spectrophotometric catechol measurement of each sample. A non-inoculated CM9 sample containing EDDA at appropriate concentrations was used as a negative control and as a spectrophotometric blank for the CAS liquid assay.

RNA purification and RT-PCR. $V$. anguillarum RV22 $10 \mathrm{ml}$ cultures were grown until exponential phase in high- and low-iron CM9 medium containing EDDA at $5 \mu \mathrm{M}$ or $\mathrm{Fe}_{2}\left(\mathrm{SO}_{4}\right)_{3}$ at $10 \mu \mathrm{M}$, and total RNA was isolated with the RNA isolation reagent RNAwiz (Ambion) following the manufacturer's recommendations. RT-PCR reactions were performed with $1 \mu \mathrm{g}$ RNA pre-treated with RQ1 RNase-Free DNase (Promega) by using the M-MLV reverse transcriptase (Invitrogen). A negative control reaction for PCR was performed with total RNA without M-MLV reverse transcriptase to confirm the lack of genomic DNA contamination in each reaction mixture. All the primers used to amplify the cDNA from putative $v a b R, v a b G, v a b A$, $v a b C E, \quad v a b H F S B$ and $f v t A v a b D$ transcripts are listed in Supplementary Table S1. The operonic nature of the genes described in this study was tested by designing appropriate primers for reverse transcription located at the $3^{\prime}$ end of the last gene for each predicted operon, and were named RT-1 to RT-6 (Fig. 2b).

\section{Construction of lacZ transcriptional fusions, and $\boldsymbol{\beta}$-galactosi-} dase assays. DNA fragments corresponding to $V$. anguillarum presumptive $v a b R, v a b G, v a b A, v a b C, v a b H$ and $f v t A$ promoter regions were obtained by PCR. The PCR-amplified putative promoter regions extended from about 300-700 bp upstream of the ATG start codon to about $50-100$ bp downstream of the start codon for each tested gene. Thus, DNA fragments containing the putative promoter regions as well as additional nucleotides of the coding sequence were fused to a promoterless lac $Z$ gene in the low-copy-number reporter plasmid pHRP309 (Parales \& Harwood, 1993). The resulting transcriptional fusion constructs, $v a b R$ : : lacZ (pMB34), vabG:: lac $Z$ (pMB33), vabA:: lacZ (pMB19), vabC:: lacZ (pMB20), vabH:: lacZ (pMB12) and fvtA:: lacZ (pMB11), were mobilized from E. coli S17-1 $\lambda$ pir to $V$. anguillarum strains RV22 and 775 met11 fur mutant by conjugation. The $V$. anguillarum strains carrying the promoter-lac $Z$ fusion vector or control plasmid pHRP309 were grown in minimal medium CM9 under different iron-availability conditions. The $\beta$ galactosidase activities were measured by the method of Miller (1992). The data presented correspond to the mean of three independent experiments. When needed, purified vanchrobactin was obtained as previously described (Soengas et al., 2006) and used at $15 \mathrm{ng} \mathrm{ml}^{-1}$.

Fur titration assay (FURTA). The same DNA fragments used in lac $Z$ transcriptional fusions, corresponding to presumptive promoter regions, were cloned in plasmid pT7-7 and transformed into the E. coli H1717 reporter strain (Hantke, 1987). The empty vector was used as a negative control. The colonies obtained were streaked onto MacConkey-lactose plates supplemented with $40 \mu \mathrm{M}$ ferric ammonium sulfate, as described elsewhere (Stojiljkovic et al., 1994). The phenotype of colonies was checked after $24-48 \mathrm{~h}$ of incubation at $37^{\circ} \mathrm{C}$. Red colonies ( $\mathrm{Lac}+$ ) denote a FURTApositive phenotype and indicate binding of the Fur protein to the promoter region transformed in the indicator strain (Stojiljkovic et al., 1994).

Cross-feeding assays. The biological activities of the supernatants produced by parental and mutant strains were determined by crossfeeding experiments. We tested the ability of cell cultures of $V$. anguillarum siderophore-defective mutants (Table 1) to cross-feed different indicator strains that were defective in DHBA and/or siderophore synthesis. Two RV22 mutant strains that are deficient in vanchrobactin biosynthesis were used to detect vanchrobactin and DHBA production. Strain MB11 is a VabB-defective mutant, unable to produce DHBA (a step between chorismate and DHBA is blocked), and consequently it can use vanchrobactin and the intermediate DHBA to overcome iron limitation. The MB14 strain is blocked in the vanchrobactin assembly process (VabF-defective mutant), and thus it can only use vanchrobactin for iron supply, and not DHBA (Balado et al., 2006).

Each indicator strain was inoculated into CM9 minimal medium containing 2,2'-dipyridyl at $80 \mu \mathrm{M}$, a concentration higher than the MIC for these strains. Strains to be tested were cultured on LB agar plates supplemented with $100 \mu \mathrm{M} 2,2^{\prime}$-dipyridyl to induce activation of siderophore biosynthesis genes. The cells were harvested with a sterile loop and placed on top of the indicator strain plates. The results were scored as positive when tester cells promoted the growth of indicator strains. The RV22 strain was used as a positive control. 
(a) Fur box
Fur box
GATAATAATATCATTACG

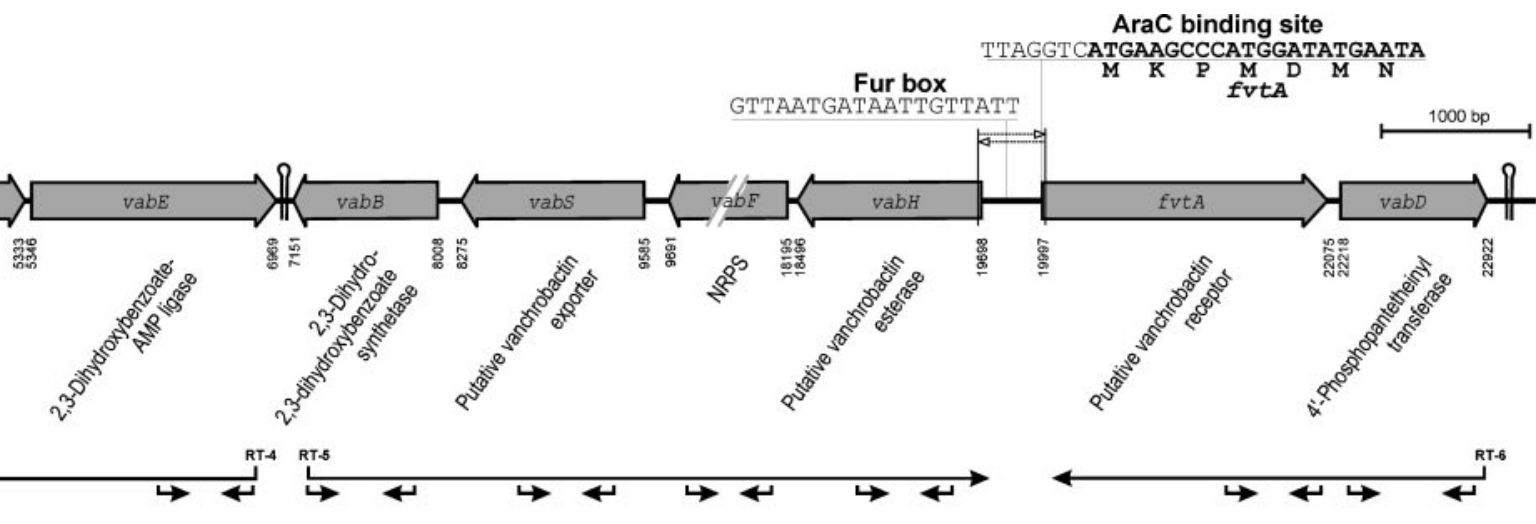

(b)
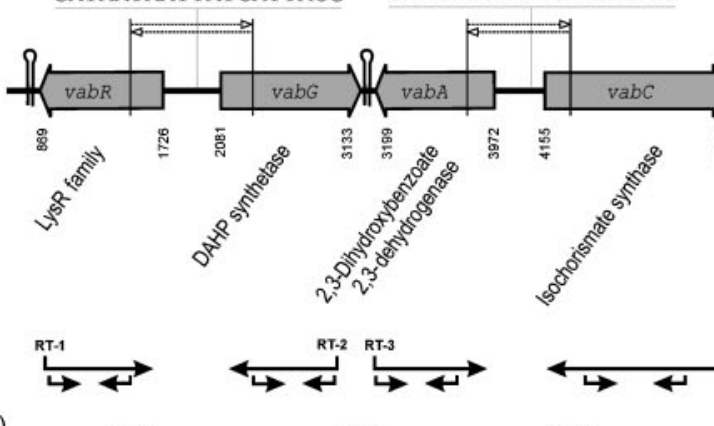

RTA RT
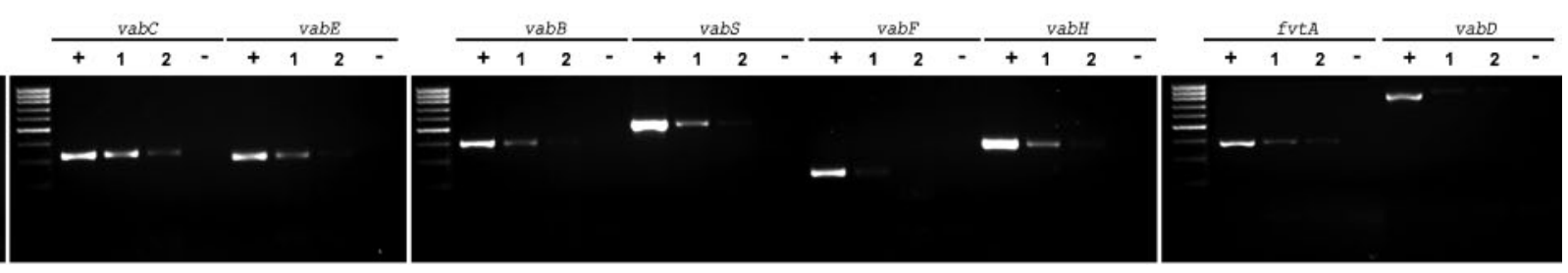

Fig. 2. (a) Physical map of the vanchrobactin biosynthesis genes of $V$. anguillarum RV22. ORFs are depicted as arrows, which indicate the direction of transcription, and the vertical numbers show the start and end points of each gene. Stem-loop structures denote putative transcriptional terminators. Dashed arrows with empty arrowheads show the regions and orientation used in transcriptional fusions. Predicted Fur boxes and a putative AraC box are shown above the ORFs. The predicted function for each gene product is shown under the ORFs. (b) Results of RT-PCR for operon mapping and for determination of iron regulation. RT denotes the binding site for primers used in reverse transcription (RT-1 to RT-6). Pairs of arrows facing each other denote the gene-specific primer pairs used in the subsequent PCR reactions. RNA for RT-PCR was purified from cells cultured under low-iron (1) and high-iron (2) conditions. Positive (+) controls are PCR reactions using chromosomal DNA as a template; negative controls $(-)$ are PCR reactions without reverse transcriptase. 


\section{RESULTS AND DISCUSSION}

\section{Cloning of new ORFs linked to vanchrobactin biosynthesis genes}

In a previous work, we described seven clustered genes involved in the biosynthesis and utilization of the siderophore vanchrobactin in $V$. anguillarum RV22 and proposed a preliminary model for vanchrobactin biosynthesis (Balado et al., 2006). However, some of the functions necessary to complete the vanchrobactin biosynthesis pathway remained undescribed. In the present study, we have identified additional pieces in the biosynthetic pathway, and a new vanchrobactin biosynthesis and uptake model that now includes regulatory factors is presented in Fig. 1. We constructed a cosmid library from $V$. anguillarum RV22 and isolated three overlapping cosmids that hybridized with the vanchrobactin synthesis genes previously described (Balado et al., 2006). Sequencing of the novel DNA contained in these cosmids resulted in the addition to the previously reported vanchrobactin gene cluster of four novel genes: vabR, vabG, fvtA and $v a b D$ (Fig. 2a). Downstream of the previously described $v a b A$ gene, we found genes $v a b G$ and $v a b R$, which are transcribed from a divergently oriented promoter. The predicted VabG protein shows high similarity to members of the E. colitype DAHP synthase family (Table 2). The deduced amino acid sequence of VabR shows similarity to several members of the LysR family of transcriptional activators (Schell, 1993). At the opposite side of this cluster, we found two genes downstream of $v a b H$ that are transcribed from the same DNA strand. The gene $f v t A$ encodes a protein that shows similarity to a series of TonB-dependent outer membrane siderophore receptors, and its location linked to the biosynthesis genes suggests that this protein might be the receptor for the ferri-vanchrobactin complex. FvtA shows a $31 \%$ identity to ViuA, the vibriobactin receptor of Vibrio cholerae (Butterton et al., 1992), and to VuuA, the vulnibactin receptor of Vibrio vulnificus (Webster \& Litwin, 2000). The $v a b D$ gene encodes a predicted PPTase (Table 2), and shows a $29 \%$ identity to angD, a plasmidharboured gene described in anguibactin-producing $V$. anguillarum strains, and which proves to encode a functional PPTase (Liu et al., 2005). We further sequenced the DNA regions in the vicinity of the vab cluster. Downstream of $v a b R$ we found two ORFs encoding a putative TonB-dependent outer membrane receptor, whose closest homologues have not been functionally characterized, and a putative lipase/esterase (data not shown). Downstream of $v a b D$ we found an ORF encoding a predicted protein which showed similarity to the $\mathrm{E}$ subunit of $\mathrm{Na}^{+}$-translocating $\mathrm{NADH}$-quinone reductases.

\section{VabD and VabG are new pieces in the vanchrobactin biosynthesis pathway}

VabD is a putative PPTase (Table 2). We constructed by allelic exchange a vabD-defective mutant (strain MB67) and tested its ability to produce siderophores and to grow under iron limitation. Under iron-sufficient conditions, no significant differences in growth levels were observed with respect to the parental strain RV22. However, MB67 $(\Delta v a b D)$ was impaired for growth under iron-restricted conditions (CM9 plus $5 \mu \mathrm{M}$ EDDA) (Fig. 3a). We predict that a mutation in this gene would not prevent DHBA production, while siderophore assembly should in turn be abolished. As expected, the CAS test showed no detectable levels of siderophore production in the $v a b D$ mutant (Fig. 3b), whereas significant levels of DHBA production were observed (Fig. 3c). These observations were further supported by the results obtained with the cross-feeding assays (Table 3). MB67 (vabD mutant) promoted growth of MB11 ( $v a b B$ mutant); this may be explained by the accumulation of DHBA by MB67, which can be used by MB11 to complete vanchrobactin production. However,

Table 2. Proteins with homology to products of $V$. anguillarum genes $v a b D, v a b G$ and $v a b R$

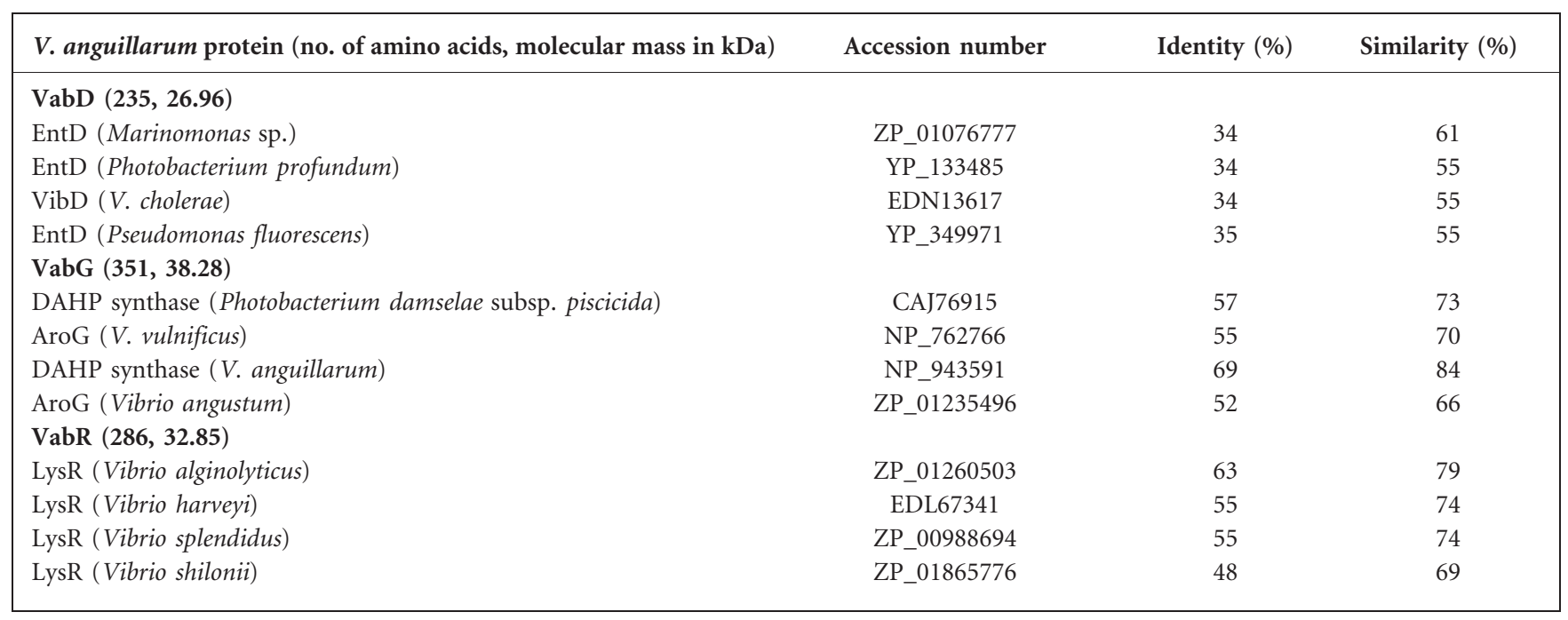




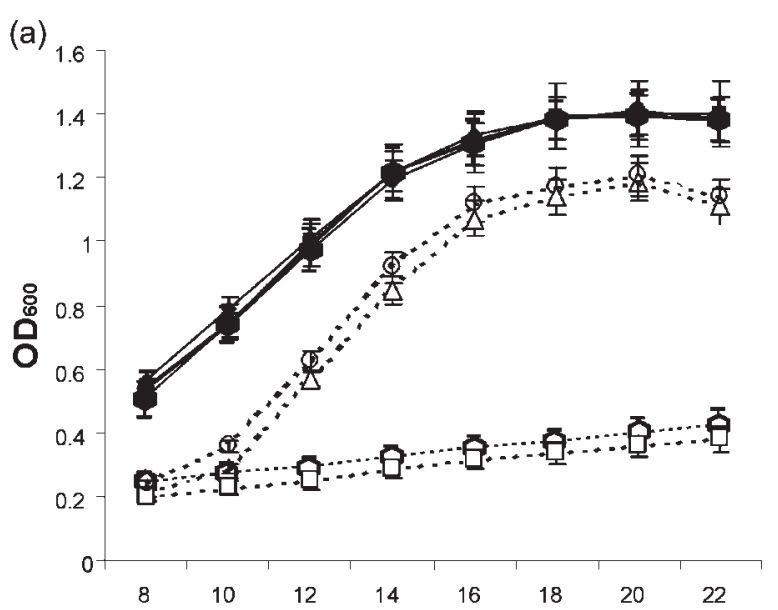

(b)
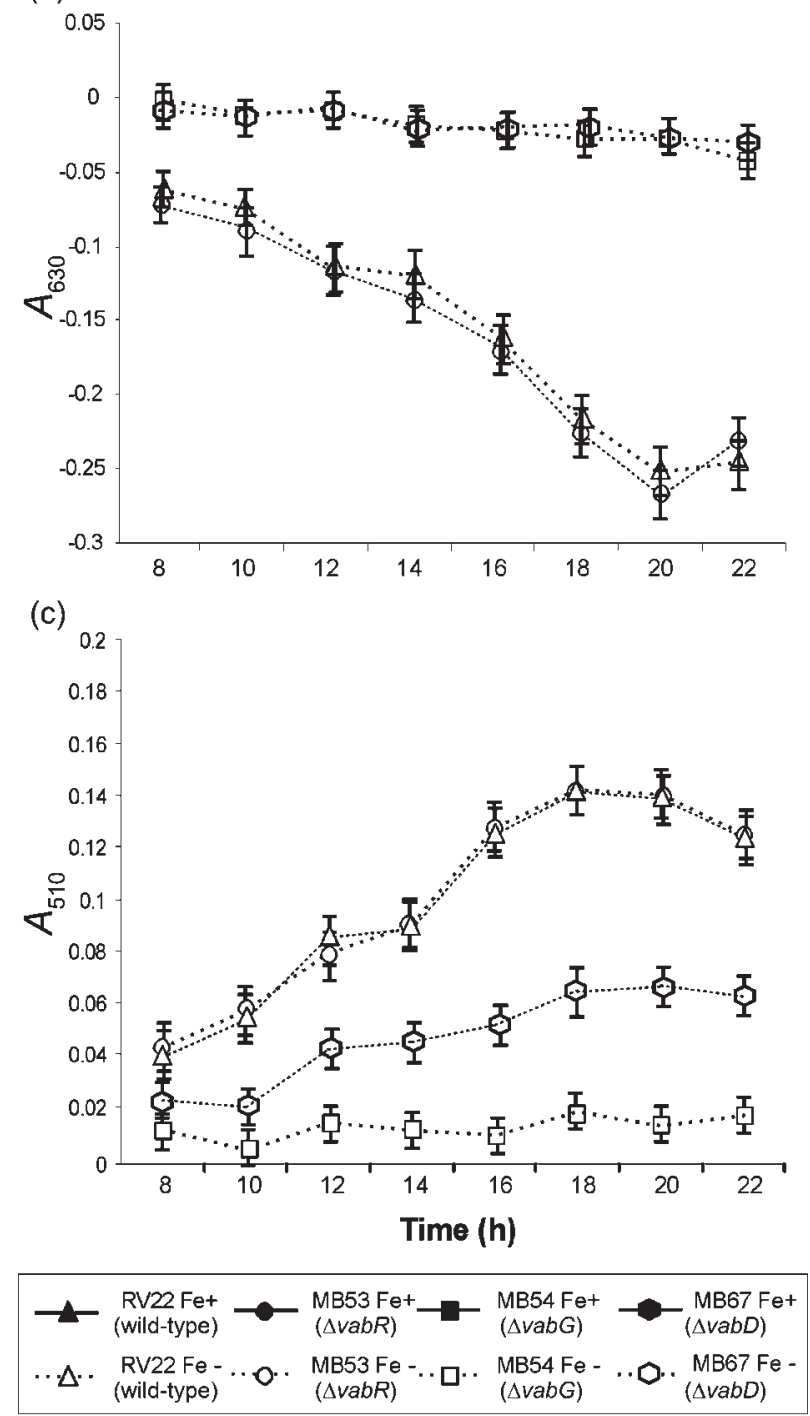

MB67 could not cross-feed MB14 (vabF mutant), which can only use vanchrobactin. These results clearly demonstrate that $v a b D$ is essential for the biosynthesis of
Fig. 3. (a) Growth $\left(\mathrm{OD}_{600}\right)$ of $V$. anguillarum RV22, MB53 $(\Delta v a b R)$, MB54 $(\Delta v a b G)$ and MB67 $(\Delta v a b D)$ strains in CM9 minimal medium under iron-sufficient $(\mathrm{Fe}+; 10 \mu \mathrm{M}$ ferric sulfate) and iron-deficient ( $\mathrm{Fe}-; 5 \mu \mathrm{M}$ EDDA) conditions. (b) Siderophore production measured by the CAS supernatant assay $\left(A_{630}\right)$. (c) DHBA production measured by the Arnow test $\left(A_{510}\right)$. In the CAS assay, lower values indicate higher siderophore production. Results are expressed as mean \pm SD from three independent experiments.

vanchrobactin and for the growth of $V$. anguillarum RV22 under iron limitation.

A vabD homologue ( $a n g D)$ has recently been described in $V$. anguillarum strains that synthesize the siderophore anguibactin, and this gene proves to encode a functional PPTase (Liu et al., 2005). AngD encodes a protein that shows $29 \%$ identity to the RV22 VabD protein. Based on protein similarity data and on our studies with the $v a b D$ mutant, VabD is likely the PPTase involved in vanchrobactin biosynthesis, playing a role in the post-translational phosphopantetheinylation of the aryl carrier protein (ArCP) domain of $\mathrm{VabB}$ and the two peptide carrier protein (PCP) domains of VabF (Balado et al., 2006).

Gene $v a b G$ encodes a putative DAHP synthase (Table 2). DAHP synthases are key enzymes in the shikimate pathway, which leads to the biosynthesis of aromatic amino acids and of numerous secondary metabolites derived from them (Hodgson, 2000), and are strictly regulated via a series of complex mechanisms (Panina et al., 2001). Vanchrobactin, as a catecholate siderophore, contains DHBA in its structure (Soengas et al., 2006), and this molecule is itself synthesized from chorismate via the shikimate pathway. To ascertain the role of $v a b G$ in vanchrobactin biosynthesis, a non-polar defective mutant was constructed by allelic exchange. When this mutant (strain MB54) was cultured in iron-sufficient conditions (CM9 plus $10 \mu \mathrm{M}$ ferric sulfate), no significant differences in growth levels were observed with respect to the parental strain RV22 (Fig. 3a). However, the MB54 $(\Delta v a b G)$ mutant was severely affected in its ability to grow under iron-restricted conditions (CM9 plus $5 \mu \mathrm{M}$ EDDA), and chemical tests showed that siderophore and DHBA production were significantly abolished in this mutant (Fig. 3b, c). These results demonstrate that $v a b G$ is essential for growth of $V$. anguillarum RV22 under iron-limiting conditions, and suggest that VabG is part of the vanchrobactin biosynthesis pathway, acting as a putative DAHP synthase. Although other DAHP synthase genes have been described linked to siderophore biosynthesis gene clusters (Osorio et al., 2006), we believe that our results represent the first experimental evidence of a DAHP synthase gene whose function is necessary for optimal siderophore production.

To test whether vanchrobactin biosynthesis is either partially or completely abolished in the $v a b G$ mutant, we tested the ability of strain MB54 to cross-feed a series of 
Table 3. Results of cross-feeding experiments

The tester strains are listed in the column at the left, and their ability to cross-feed the four indicator mutant strains MB54, MB67, MB11 and MB14 is scored as positive, negative, or weak positive. NA, Not applicable; $(+)$, weak positive.

\begin{tabular}{|c|c|c|c|c|}
\hline \multirow[t]{2}{*}{ Strain } & \multicolumn{4}{|c|}{ Ability to cross-feed } \\
\hline & MB54 $(\Delta v a b G)$ & $\operatorname{MB67}(\Delta v a b D)$ & $\operatorname{MB} 11(\Delta v a b B)$ & $\operatorname{MB14}(\Delta v a b F)$ \\
\hline $\operatorname{MB} 54(\Delta v a b G)$ & $\mathrm{NA}$ & $(+)$ & $(+)$ & $(+)$ \\
\hline $\operatorname{MB67}(\Delta v a b D)$ & + & NA & + & - \\
\hline $\operatorname{MB} 11(\Delta v a b B)$ & + & - & $\mathrm{NA}$ & - \\
\hline $\operatorname{MB} 14(\Delta v a b F)$ & + & - & + & NA \\
\hline RV22 & + & + & + & + \\
\hline
\end{tabular}

vanchrobactin-deficient indicator strains (Table 3). Surprisingly, we found that the MB54 mutant was able to induce low levels of growth of MB14, a $v a b F$ mutant that can only use vanchrobactin to overcome the iron limitation. Similarly, MB54 also cross-fed MB11 $(\Delta v a b B)$, which can use both vanchrobactin and DHBA (Table 3 ). These results indicate that, although vanchrobactin biosynthesis is significantly reduced in the $v a b G$ mutant, it is not completely abolished. This observation would suggest that another gene or genes in $V$. anguillarum encodes a DAHP synthase activity that can partially, but not completely, substitute for the VabG function. This being the case, one gene could encode an isoenzyme mainly involved in the production of extra chorismate molecules for siderophore biosynthesis, while keeping a paralogue involved in the production of aromatic amino acids. In E. coli and other Gram-negative bacteria such as $V$. cholerae, up to three paralogous DAHP synthase genes (aroF, aroG and aroH), involved exclusively in amino acid biosynthesis, have been described coexisting in the same genome (Panina et al., 2001, 2003). The necessity of having a specific isoenzyme involved in siderophore production is motivated by the fact that the paralogues involved in aromatic amino acid production are strictly regulated at the transcriptional (Pittard et al., 2005), translational (Yanofsky, 2000), and enzymic activity levels (Pittard et al., 2005). The interconnection between the biosynthetic routes leading to siderophore biosynthesis and to amino acids (two routes that share chorismate as an intermediate) has been recently evidenced in a Bacillus subtilis transcriptome study (Miethke et al., 2006). These authors found that 11 amino acid biosynthesis genes were more than $40 \%$ upregulated during iron starvation, and all of them encoded enzymes that are essential for the synthesis of the precursors threonine, glycine and DHBA of the siderophore bacillibactin.

\section{The vanchrobactin biosynthesis gene cluster is organized into six iron-regulated transcriptional units}

The three intergenic regions vabR-vabG, vabA-vabC and $v a b H-f v t A$ show a structure of divergent promoters.
Moreover, two putative Rho-independent transcriptional terminators were located by in silico analysis between the $v a b G-v a b A$ and $v a b E-v a b B$ stop codons (Fig. 2a). All these observations suggest that the $V$. anguillarum vanchrobactin biosynthesis gene cluster is organized in six transcriptional units: vabR, vabG, vabA, vabCE, vabHFSB and fvtAvabD. To confirm the transcriptional association of the three putative polycistronic messages, we carried out reversetranscription reactions using primers located at the $3^{\prime}$ end of the last gene for each predicted operon (primers RT-1 to RT-6 in Fig. 2b), and subsequent gene-specific PCR reactions were conducted. These RT-PCR experiments were carried out using RNA purified under conditions of both iron deficiency and iron sufficiency. The results obtained in this assay (Fig. 2b) confirmed the existence of three polycistronic mRNAs, one comprising the vabH, $v a b F$, vabS and $v a b B$ genes, the second comprising $v a b C$ and $v a b E$, and the last $f v t A$ and $v a b D$. However, these results do not rule out the possibility that additional promoters exist within this cluster, and may drive independent transcription of some of the genes. In addition, the transcripts of the six predicted transcriptional units were shown to be weakly expressed under iron-rich conditions (10 $\mu \mathrm{M}$ ferrous sulfate) (Fig. 2b), whereas the intensity of the bands was significantly increased when using RNA samples from cultures supplemented with the iron chelator EDDA $(5 \mu \mathrm{M})$. Although RT-PCR carried out under these conditions is not the most accurate quantitative assay for RNA levels, it provides evidence that the expression of the genes of this cluster is indeed subject to regulation by iron.

\section{The putative promoter regions contain consensus sequences for the binding of negative and positive regulators}

Examination of the intergenic sequences of this cluster revealed three conserved Fur binding sites (Fig. 2a). The intergenic region $v a b R-v a b G$ harbours a putative Fur box (GATAATAATTATCATTACG) with an identity of 15 out of 19 positions to the E. coli consensus iron box (de Lorenzo et al., 1987) (the positions identical to the consensus are underlined). Two similar sequences, 
GTTAATGATAATTGTTATT and GTTATTGATAATTATTATC, were found in the intergenic regions $v a b H-$ $f v t A$ and $v a b A-v a b C$ (Fig. 2a). The presence of these Fur binding sites would suggest that the Fur repressor exerts iron-dependent regulation of vanchrobactin synthesis genes. In order to gain further evidence that these promoters contain sequences for the binding of Fur, FURTA was carried out as described elsewhere (Stojiljkovic et al., 1994) by cloning the presumptive promoter sequences containing potential Fur boxes into the FURTA indicator strain H1717 (Hantke, 1987). As a result, all the cloned promoters showed a typical FURTA-positive phenotype (evidenced as Lac + colonies on MacConkey agar plates supplemented with excess iron), which suggests that the cloned sequences harbour sites for binding of the E. coli Fur protein.

In addition to the Fur-mediated repression, transcriptional regulators with a positive action have been described as playing roles in gene regulation (Chen \& Crosa, 1996; Gallegos et al., 1997). We therefore subjected the promoter sequences of this cluster to the PRODORIC database using the Virtual Footprint promoter analysis software, and as a result we predicted a putative AraC-type regulator binding site (TATTCATATCCATGGGCTTCATGACCTAA) in the negative strand of the fvtA gene, which includes the fvtA start codon (Fig. 2a).

\section{Transcriptional lacZ fusions demonstrate that expression of vanchrobactin synthesis genes is iron regulated}

To define the promoter activities and test whether the ironmediated regulation of the vanchrobactin biosynthesis gene cluster occurred at the transcriptional level, as suggested by the RT-PCR results (Fig. 2b), we constructed transcriptional fusions and examined their expression under highand low-iron conditions. As a control, V. anguillarum RV22 carrying the pHRP309 plasmid without any promoter was analysed in parallel, exhibiting almost undetectable levels of $\beta$-galactosidase activity under all the growth conditions tested (data not shown). When the constructions were assayed in $V$. anguillarum RV22, high $\beta$-galactosidase activities were observed for $v a b R:: l a c Z, v a b G:: l a c Z$, $v a b H:: l a c Z$, fvtA::lacZ, vabC::lacZ and vabA::lacZ fusions in low-iron medium (CM9 plus EDDA at $5 \mu \mathrm{M}$ ), whereas the addition of $10 \mu \mathrm{M} \mathrm{Fe}{ }_{2}\left(\mathrm{SO}_{4}\right)_{3}$ to the culture medium resulted in the lowest $\beta$-galactosidase activity, indicating repression of promoter activity (Fig. 4). All the fusions with the exception of $v a b R$ ::lacZ showed a reduction of $\sim 90 \%$ in their expression patterns under high-iron conditions with respect to levels shown under low-iron conditions (Fig. 4). In the case of the vabR:: lacZ construction, this reduction was about $50 \%$. The transcriptional repression observed under iron-replete conditions is consistent with a predicted role for Fur in regulation. To demonstrate that the observed repression is indeed Furmediated, the fusions were conjugated into the $V$. anguillarum fur mutant strain 775met11 (Tolmasky et al., 1994). The same iron conditions utilized for RV22 were now assayed with 775 met 11, and results are summarized in Fig. 4. Iron-dependent repression of promoters was not detected when the vabH::lacZ, fvtA::lacZ, vabC::lacZ and $v a b A::$ lac $Z$ fusions were assayed in the fur mutant, and the $\beta$-galactosidase activities were high under both highand low-iron conditions, indicating that these promoters are constitutive in the absence of Fur.

Surprisingly, the $v a b G:: l a c Z$ and $v a b R:: l a c Z$ fusions showed an unexpected response in the fur mutant. On

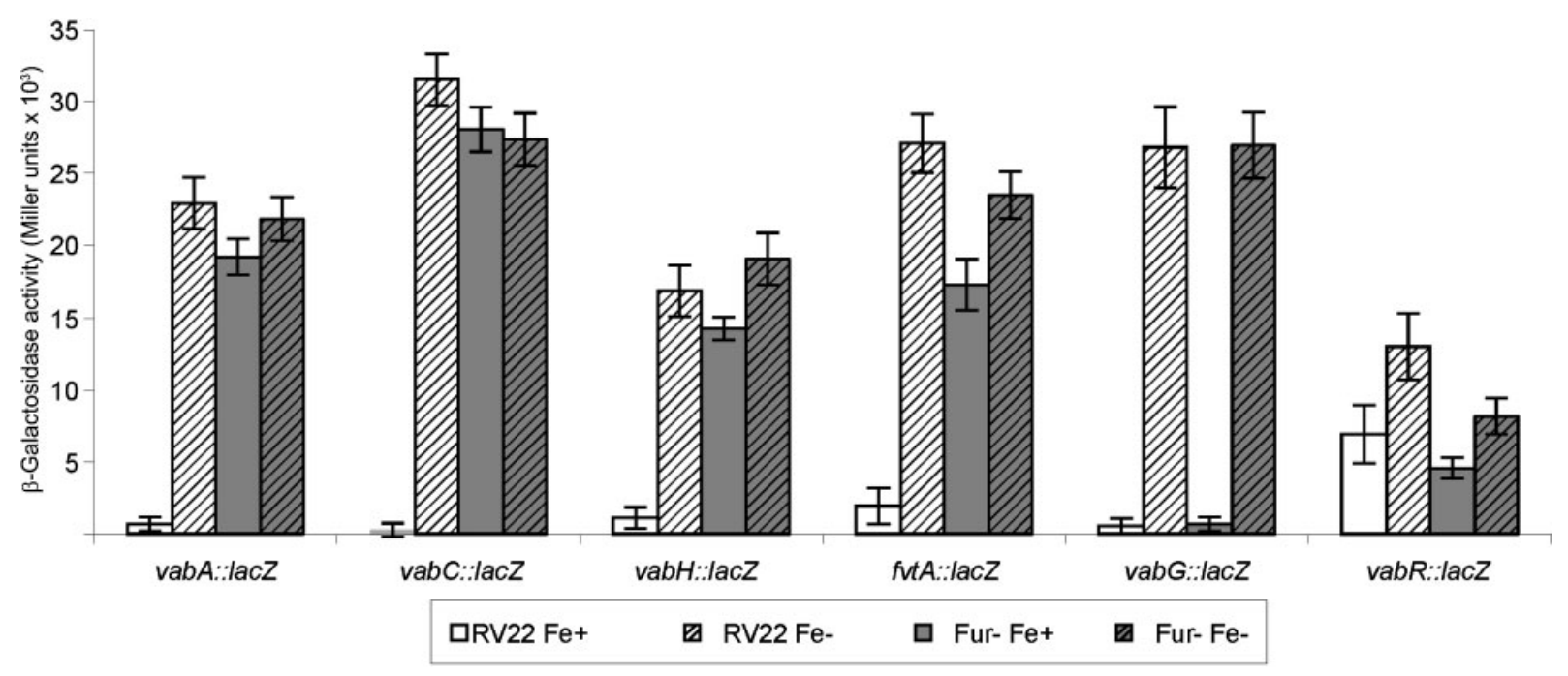

Fig. 4. Transcriptional analysis of the vanchrobactin biosynthesis genes carried out with lacZ fusions. Bars indicate $\beta$ galactosidase activities of cultures grown under iron-sufficient or iron-deficient conditions (CM9 plus $10 \mu \mathrm{M}$ ferric sulfate or $5 \mu \mathrm{M}$ EDDA). $\beta$-Galactosidase activities were assayed in the parental strain RV22 and in the 775met11 fur mutant. 
the one hand, the vabG: : lacZ fusion maintained a drastic iron-dependent repression in the fur mutant (Fig. 4). This result indicates that $v a b G$ transcriptional regulation is irondependent, but that Fur is not essential for this repression. Thus, there must be another regulator that controls the response of $v a b G$ to iron. The iron-dependent regulation of $v a b G$ is consistent with the above suggested role of VabG as a DAHP synthase mainly involved in siderophore biosynthesis.

Furthermore, the $v a b R:: l a c Z$ fusion maintained the reduction in $\beta$-galactosidase levels under high-iron conditions at $55 \pm 12 \%$ of the levels shown under low-iron conditions. This fusion showed a similar $\beta$-galactosidase activity reduction in the Fur-deficient strain $(64 \pm 16 \%)$, which indicates that some levels of iron-mediated repression are still present in the absence of Fur (Fig. 4). This therefore suggests that Fur is not the main iron-responsive regulator of $v a b R$. Notably, the maximal expression of the $v a b R$ :: lacZ fusion achieved in strain 775 met11 was reduced by more than $40 \%$ when compared to expression levels in the RV22 strain. This reduction could be explained in part by the fact that the 775met11 strain is not isogenic with RV22 and does not produce vanchrobactin.

The results obtained with $v a b G:: l a c Z$ and $v a b R:: l a c Z$ fusions suggest the necessary existence of additional regulation mechanisms different from Fur. Our results clearly indicate that: (1) $v a b G$ and $v a b R$ are iron regulated; (2) there is evidence that the $v a b G-v a b R$ intergenic region harbours a Fur box, since it yields a strong FURTA-positive phenotype when transformed into the indicator strain $\mathrm{H} 1717$; (3) these results do not rule out the possibility that Fur plays a significant role in the regulation of either $v a b G$ or $v a b R$, or both. In the absence of Fur, we found evidence of a strong iron-mediated repression. It could be that the repression of $v a b G / v a b R$ is carried out by Fur as well as by a yet uncharacterized repressor, and that in the absence of Fur, this second repressor by itself accounts for nearly the same level of repression. Additional studies would be necessary to understand the role of the Fur-mediated repression in the expression of these two genes. It is also recognized that Fur may exert its effect indirectly by altering the expression of activators required for the expression of iron-regulated genes. Studies of the regulation of anguibactin biosynthesis genes, encoded in the pJM1 plasmid, have demonstrated that, in addition to the general mechanism mediated by Fur repression (Tolmasky \& Crosa, 1991), other plasmid-encoded factors play a role in regulation, including the AngR protein (Tolmasky et al., 1993; Wertheimer et al., 1999), the trans-acting factor(s) (TAF) (Welch et al., 2000), and an antisense RNA, RNA $\alpha$ (Chen \& Crosa, 1996; Stork et al., 2007).

Thus, transcriptional lac $Z$ fusions evaluated under lowand high-iron conditions demonstrate that all these genes are strongly iron regulated, as suggested by the RT-PCR experiments (see above). However, the data we obtained using the two approaches do not show an exact correlation.
As an example, the expression of the $v a b G$ gene promoter showed a strong repression under high-iron conditions when measured by $\beta$-galactosidase assays, whereas the respective RT-PCR assay still showed a detectable amount of PCR product (Fig. 2b). We consider that the studies of lac $Z$ fusion data are more suitable for quantitative comparisons than the RT-PCR assays, since the PCR-based exponential amplification of the RNA transcripts originally present in the sample could lead to an overestimation of the actual gene expression levels.

\section{vabR encodes a putative LysR-family activator, and its deletion affects vabG expression}

VabR is similar to members of the LTTR family, which is the largest family of prokaryotic DNA-binding transcriptional factors (Schell, 1993). The domain analysis of VabR (a total of 286 residues) shows a LysR substrate domain from residues 61 to 278 , which includes the helix-turnhelix DNA-binding motif at its $\mathrm{N}$ terminus. Most LTTRs are encoded by genes that are transcribed divergently from their target genes, and operate as transcriptional regulators activating expression together with a small molecule ligand that acts as a coinducer (Gallegos et al., 1997; Schell, 1993). Notably, $v a b R$ and $v a b G$ are divergently transcribed (Fig. 2a), which suggests that $v a b R$ could exert a regulatory effect on vabG. To test this hypothesis, we designed an inframe deletion mutant (MB53). This mutant did not show any significant alteration in vanchrobactin production or in the ability of $V$. anguillarum to grow under iron-limiting conditions (Fig. 3).

We then introduced the transcriptional fusion $v a b G$ : : lacZ into the $\Delta v a b R$ mutant, and compared the expression pattern from the $v a b G$ promoter with that obtained in the RV22 parental strain. As expected, this fusion was strongly repressed under conditions of iron excess, showing expression levels similar to those of the RV22 background. However, under iron-limiting conditions, the vabR mutant (MB53) strain showed a significant reduction of $\beta$ galactosidase activity of about $35-40 \%$ with respect to the wild-type RV22 (Fig. 5). These results clearly indicate that $v a b R$ encodes a regulatory factor necessary for maximal $v a b G$ expression. Other reported examples of LTTRs that cooperate with Fur in the regulation of gene expression include amino acid biosynthesis (Panina et al., 2001), virulence (Watnick et al., 1998) and iron uptake (Litwin \& Quackenbush, 2001; Vasil et al., 1998).

We have demonstrated that $v a b R$ exerts a regulatory role on the divergently transcribed $v a b G$ gene. However, it remained to be tested whether VabR also influences the expression of other vanchrobactin biosynthesis and transport genes, as well as regulating its own gene expression. To ascertain these possibilities, we introduced all the remaining gene fusions (vabH::lacZ, fvtA::lacZ, vabC::lacZ, $v a b A:: l a c Z$ and $v a b R:: l a c Z$ ) into the $v a b R$ mutant. The results demonstrated that mutation of $v a b R$ did not have any detectable effect on the $\beta$-galactosidase activities of 


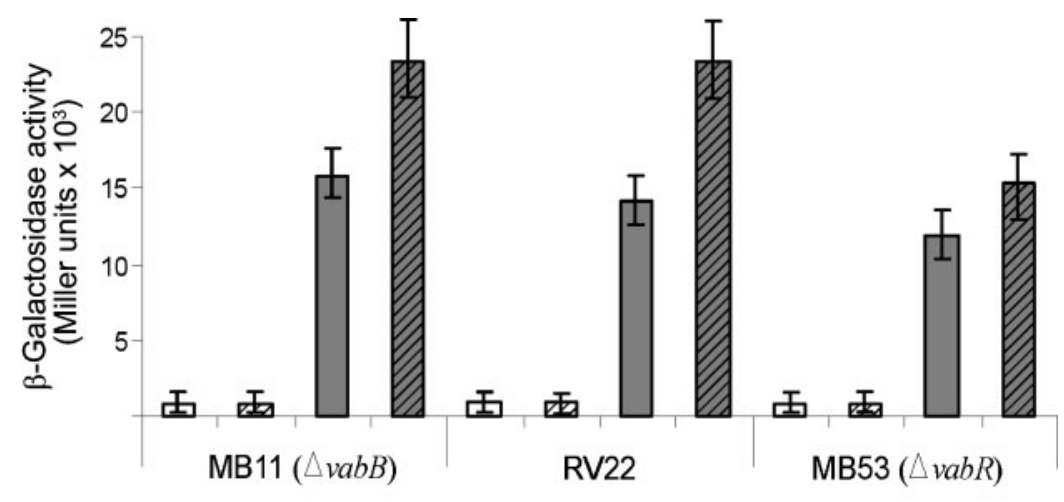

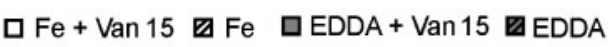

Fig. 5. Transcriptional analysis of the $v a b G$ gene promoter carried out with lac $Z$ fusions. Bars indicate $\beta$-galactosidase activities of cultures grown under iron-sufficient or irondeficient conditions (CM9 plus $10 \mu \mathrm{M}$ ferric sulfate or $1.25 \mu \mathrm{M}$ EDDA) and in presence of $15 \mathrm{ng}$ vanchrobactin $\mathrm{ml}^{-1}$ (Van 15). The $\beta$ galactosidase activity of transcriptional fusions was assayed in the parental strain RV22, in MB11 (vabB mutant) and in MB53 (vabR mutant). these promoters (data not shown). Thus, it was demonstrated that $v a b R$ transcription is not self-regulated, and that the only direct target of VabR in the cluster described in this study is $v a b G$.

We also tested whether VabR is involved in the regulation of $v a b G$ in response to vanchrobactin. To assess this possibility we measured $v a b G$ : : lacZ expression in the presence and absence of exogenously added vanchrobactin, in strains MB11 $(\Delta v a b B)$ and MB53 $(\Delta v a b R)$, as well as in the parental strain. As shown in Fig. 5, under ironsufficient conditions, no significant differences were observed in the mutants with respect to the parental strain. However, under iron-deficient conditions $(1.25 \mu \mathrm{M}$ EDDA), addition of $15 \mathrm{ng}$ vanchrobactin $\mathrm{ml}^{-1}$ caused a decrease of between 33 and $36 \%$ in the $\beta$-galactosidase values in the three assayed strains. This can be explained, as the addition of exogenous vanchrobactin is expected to produce a relaxation in the conditions of iron deficiency, leading to a lighter repression of the $v a b G$ promoter. Taking all the results into consideration, vanchrobactin is likely not involved in the VabR-mediated activation of the $v a b G$ promoter.

\section{Transcriptional analysis of fvtA : : lacZ in a vanchrobactin-deficient $v a b B$ mutant: dependence on a positive transcriptional regulator}

The promoter region of $f v t A$ contains a putative AraC box. This suggests that the fvtA gene is subjected to some kind of positive regulation. To ascertain this possibility, we introduced the $f v t A$ : : lac $Z$ fusion into the parental strain as well as into the $v a b B$ mutant (MB11), and measured the $\beta$ galactosidase activities. We used less restrictive ironlimiting conditions (1.25 $\mu \mathrm{M}$ EDDA) in order to allow growth of the $v a b B$ mutant and allow the comparison of the $v a b B$ data with those obtained with the parental strain. Under these conditions, no significant differences were observed in the $\beta$-galactosidase activity values between the parental and mutant strain (data not shown). Interestingly, under iron-rich conditions, we found that the $\beta$-galactosidase activity of the $f v t A:: l a c Z$ fusion into the $v a b B$ mutant was only $1.18 \pm 0.74 \%$ of the activity observed under conditions of iron limitation. However, this same fusion into the parental strain RV22 yielded an appreciable basal expression level $(7.3 \pm 2.1 \%$ of the expression levels under iron limitation) (Fig. 6). These results indicate that this promoter is downregulated in the absence of vanchrobactin (a sixfold decrease), and suggest that the Fe-siderophore complex plays a positive regulatory role. To test this possibility, we added purified vanchrobactin (at 15 and $30 \mathrm{ng} \mathrm{ml}^{-1}$ ) to cultures of the $v a b B$ mutant, and analysed the variation in the $\beta$-galactosidase activities of the $f v t A$ : : lac $Z$ fusion. The results showed an increase higher than threefold in the expression levels of the $f v t A$ promoter (Fig. 6). This effect was vanchrobactin-dependent in a linear fashion, since by doubling the amount of vanchrobactin the $\beta$-galactosidase activity was similarly doubled. Remarkably, the addition of vanchrobactin to the

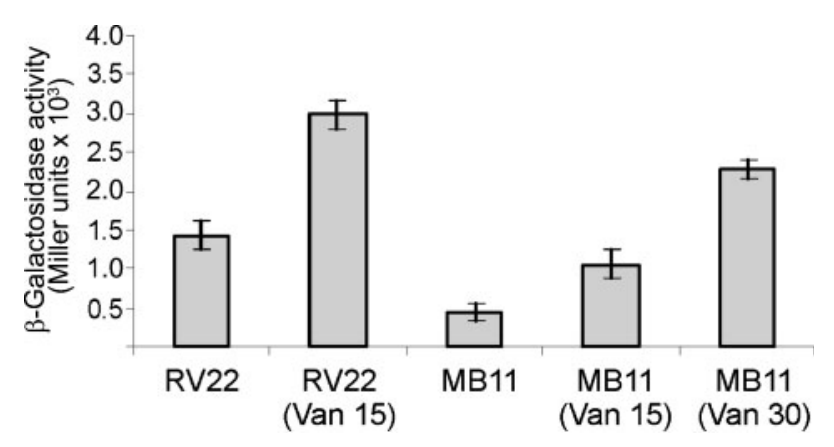

Fig. 6. Transcriptional analysis of the $f v t A$ gene promoter carried out with lac $Z$ fusions. The $\beta$-galactosidase activities are shown of cultures growing under iron-sufficient conditions (CM9 plus $10 \mu \mathrm{M}$ ferric sulfate). The $\beta$-galactosidase activity of transcriptional fusions was assayed in the parental strain RV22 and in the MB11 $(\Delta v a b B)$ vanchrobactin synthesis-defective mutant. Van 15, addition of vanchrobactin at $15 \mathrm{ng} \mathrm{m}^{-1}$; Van 30 , addition of vanchrobactin at $30 \mathrm{ng} \mathrm{ml}^{-1}$. 
parental strain harbouring the fvtA:: lacZ fusion also resulted in a similar increase (Fig. 6). We also tested whether vanchrobactin is involved in the regulation of the transcription of other genes of the cluster. The analysis of the $v a b H:$ : lacZ, vabC::lacZ, vabA::lacZ and $v a b R:$ : lac $Z$ fusions in strain MB11 $(\triangle v a b B)$ showed no significant differences in gene expression with respect to the parental strain (data not shown).

It has been reported that micro-organisms are able to sense siderophores in the extracellular environment, resulting in an upregulation of the siderophore uptake genes. One of these mechanisms is based on the activation of target genes by means of an AraC-type protein that requires the presence of the cognate siderophore to bind to specific promoter sequences (Anderson \& Armstrong, 2004; Brickman et al., 2001; Fetherston et al., 1996; Pelludat et al., 1998). It is tempting to speculate that the siderophore vanchrobactin is the effector molecule, activating a yet-uncharacterized AraC-type regulator that binds at the conserved AraC box in the fvtA promoter (Fig. 2). Our observation that the fvtA promoter is downregulated in the absence of vanchrobactin reinforces this hypothesis.

\section{Conclusion}

The results reported here indicate that the biosynthesis of the siderophore vanchrobactin in $V$. anguillarum proceeds through an NRPS-mediated pathway that is subjected to a complex regulatory network. Positive and negative regulatory mechanisms are involved, likely aimed at adjusting vanchrobactin production for the maintenance of iron homeostasis in $V$. anguillarum. A proposed model for the regulation of vanchrobactin synthesis and uptake is schematically summarized in Fig. 1. Future work will be directed to fill some of the gaps in our current knowledge of the regulatory network.

\section{ACKNOWLEDGEMENTS}

This work was supported by grant AGL2006-00697 from the Ministry of Education and Science of Spain (cofunded by the FEDER Programme from the European Union) and grant PGIDIT04RMA261014PR-3 from Xunta de Galicia to M.L.L., and M. B. is the recipient of an FPI fellowship from the Ministry of Education and Science of Spain.

\section{REFERENCES}

Alice, A. F., Lopez, C. S. \& Crosa, J. H. (2005). Plasmid- and chromosome-encoded redundant and specific functions are involved in biosynthesis of the siderophore anguibactin in Vibrio anguillarum 775: a case of chance and necessity? J Bacteriol 187, 2209-2214.

Anderson, M. T. \& Armstrong, S. K. (2004). The BfeR regulator mediates enterobactin-inducible expression of Bordetella enterobactin utilization genes. J Bacteriol 186, 7302-7311.

Arnow, L. E. (1937). Colorimetric determination of the components of 3,4 dihydroxyphenyl-alanine-tyrosine mixtures. J Biol Chem 118, $531-537$.
Balado, M., Osorio, C. R. \& Lemos, M. L. (2006). A gene cluster involved in the biosynthesis of vanchrobactin, a chromosomeencoded siderophore produced by Vibrio anguillarum. Microbiology 152, 3517-3528.

Bateman, A., Coin, L., Durbin, R., Finn, R. D., Hollich, V., GriffithsJones, S., Khanna, A., Marshall, M., Moxon, S. \& other authors (2004). The Pfam protein families database. Nucleic Acids Res 32, D138-D141.

Braun, V. \& Killmann, H. (1999). Bacterial solutions to the iron-supply problem. Trends Biochem Sci 24, 104-109.

Braun, V., Hantke, K. \& Koster, W. (1998). Bacterial iron transport: mechanisms, genetics, and regulation. Met Ions Biol Syst 35, 67-145.

Brickman, T. J., Kang, H. Y. \& Armstrong, S. K. (2001). Transcriptional activation of Bordetella alcaligin siderophore genes requires the AlcR regulator with alcaligin as inducer. J Bacteriol 183, 483-489.

Butterton, J. R., Stoebner, J. A., Payne, S. M. \& Calderwood, S. B. (1992). Cloning, sequencing, and transcriptional regulation of viuA, the gene encoding the ferric vibriobactin receptor of Vibrio cholerae. J Bacteriol 174, 3729-3738.

Challis, G. L. (2005). A widely distributed bacterial pathway for siderophore biosynthesis independent of nonribosomal peptide synthetases. ChemBioChem 6, 601-611.

Chen, Q. \& Crosa, J. H. (1996). Antisense RNA, Fur, iron, and the regulation of iron transport genes in Vibrio anguillarum. J Biol Chem 271, 18885-18891.

Chen, Q., Actis, L. A., Tolmasky, M. E. \& Crosa, J. H. (1994). Chromosome-mediated 2,3-dihydroxybenzoic acid is a precursor in the biosynthesis of the plasmid-mediated siderophore anguibactin in Vibrio anguillarum. J Bacteriol 176, 4226-4234.

Conchas, R. F., Lemos, M. L., Barja, J. L. \& Toranzo, A. E. (1991). Distribution of plasmid- and chromosome-mediated iron uptake systems in Vibrio anguillarum strains of different origins. Appl Environ Microbiol 57, 2956-2962.

Crosa, J. H. (1989). Genetics and molecular biology of siderophoremediated iron transport in bacteria. Microbiol Rev 53, 517-530.

Crosa, J. H. \& Walsh, C. T. (2002). Genetics and assembly line enzymology of siderophore biosynthesis in bacteria. Microbiol Mol Biol Rev 66, 223-249.

de Lorenzo, V., Wee, S., Herrero, M. \& Neilands, J. B. (1987). Operator sequences of the aerobactin operon of plasmid ColV-K30 binding the ferric uptake regulation (fur) repressor. J Bacteriol 169, 2624-2630.

Di Lorenzo, M., Stork, M., Tolmasky, M. E., Actis, L. A., Farrell, D., Welch, T. J., Crosa, L. M., Wertheimer, A. M., Chen, Q. \& other authors (2003). Complete sequence of virulence plasmid pJM1 from the marine fish pathogen Vibrio anguillarum strain 775. J Bacteriol 185, 5822-5830.

Escolar, L., Perez-Martin, J. \& de Lorenzo, V. (1999). Opening the iron box: transcriptional metalloregulation by the Fur protein. J Bacteriol 181, 6223-6229.

Fetherston, J. D., Bearden, S. W. \& Perry, R. D. (1996). YbtA, an AraC-type regulator of the Yersinia pestis pesticin/yersiniabactin receptor. Mol Microbiol 22, 315-325.

Gallegos, M. T., Schleif, R., Bairoch, A., Hofmann, K. \& Ramos, J. L. (1997). AraC/XylS family of transcriptional regulators. Microbiol Mol Biol Rev 61, 393-410.

Hall, T. A. (1999). BioEdit: a user-friendly biological sequence alignment editor and analysis program for Windows 95/98/NT. Nucleic Acids Symp Ser 41, 95-98.

Hantke, K. (1987). Selection procedure for deregulated iron transport mutants (fur) in Escherichia coli K 12: fur not only affects iron metabolism. Mol Gen Genet 210, 135-139. 
Herrero, M., de Lorenzo, V. \& Timmis, K. N. (1990). Transposon vectors containing non-antibiotic resistance selection markers for cloning and stable chromosomal insertion of foreign genes in Gramnegative bacteria. J Bacteriol 172, 6557-6567.

Hodgson, D. A. (2000). Primary metabolism and its control in streptomycetes: a most unusual group of bacteria. Adv Microb Physiol 42, 47-238.

Kloosterman, H., Hessels, G. I., Vrijbloed, J. W., Euverink, G. J. \& Dijkhuizen, L. (2003). (De)regulation of key enzyme steps in the shikimate pathway and phenylalanine-specific pathway of the actinomycete Amycolatopsis methanolica. Microbiology 149, 3321-3330.

Lemos, M. L., Salinas, P., Toranzo, A. E., Barja, J. L. \& Crosa, J. H. (1988). Chromosome-mediated iron uptake system in pathogenic strains of Vibrio anguillarum. J Bacteriol 170, 1920-1925.

Litwin, C. M. \& Quackenbush, J. (2001). Characterization of a Vibrio vulnificus LysR homologue, HupR, which regulates expression of the haem uptake outer membrane protein, HupA. Microb Pathog 31, 295-307.

Liu, Q., Ma, Y., Zhou, L. \& Zhang, Y. (2005). Gene cloning, expression and functional characterization of a phosphopantetheinyl transferase from Vibrio anguillarum serotype O1. Arch Microbiol 183, 37-44.

Masse, E. \& Gottesman, S. (2002). A small RNA regulates the expression of genes involved in iron metabolism in Escherichia coli. Proc Natl Acad Sci U S A 99, 4620-4625.

Michel, L., Gonzalez, N., Jagdeep, S., Nguyen-Ngoc, T. \& Reimmann, C. (2005). PchR-box recognition by the AraC-type regulator PchR of Pseudomonas aeruginosa requires the siderophore pyochelin as an effector. Mol Microbiol 58, 495-509.

Miethke, M., Westers, H., Blom, E. J., Kuipers, O. P. \& Marahiel, M. A. (2006). Iron starvation triggers the stringent response and induces amino acid biosynthesis for bacillibactin production in Bacillus subtilis. J Bacteriol 188, 8655-8657.

Miller, J. H. (1992). A Short Course in Bacterial Genetics. Plainview, NY: Cold Spring Harbor Laboratory.

Mouriño, S., Osorio, C. R. \& Lemos, M. L. (2004). Characterization of heme uptake cluster genes in the fish pathogen Vibrio anguillarum. J Bacteriol 186, 6159-6167.

Osorio, C. R., Juiz-Rio, S. \& Lemos, M. L. (2006). A siderophore biosynthesis gene cluster from the fish pathogen Photobacterium damselae subsp. piscicida is structurally and functionally related to the Yersinia high-pathogenicity island. Microbiology 152, 3327-3341.

Panina, E. M., Vitreschak, A. G., Mironov, A. A. \& Gelfand, M. S. (2001). Regulation of aromatic amino acid biosynthesis in gammaproteobacteria. J Mol Microbiol Biotechnol 3, 529-543.

Panina, E. M., Vitreschak, A. G., Mironov, A. A. \& Gelfand, M. S. (2003). Regulation of biosynthesis and transport of aromatic amino acids in low-GC Gram-positive bacteria. FEMS Microbiol Lett 222, 211-220.

Parales, R. E. \& Harwood, C. S. (1993). Construction and use of a new broad-host-range lac $Z$ transcriptional fusion vector, pHRP309, for $\mathrm{Gram}^{-}$bacteria. Gene 133, 23-30.

Pelludat, C., Rakin, A., Jacobi, C. A., Schubert, S. \& Heesemann, J. (1998). The yersiniabactin biosynthetic gene cluster of Yersinia enterocolitica: organization and siderophore-dependent regulation. J Bacteriol 180, 538-546.

Pittard, J., Camakaris, H. \& Yang, J. (2005). The TyrR regulon. Mol Microbiol 55, 16-26.

Ratledge, C. \& Dover, L. G. (2000). Iron metabolism in pathogenic bacteria. Annu Rev Microbiol 54, 881-941.
Sambrook, J. \& Russell, D. W. (2001). Molecular Cloning: a Laboratory Manual. Cold Spring Harbor, NY: Cold Spring Harbor Laboratory.

Schell, M. A. (1993). Molecular biology of the LysR family of transcriptional regulators. Annu Rev Microbiol 47, 597-626.

Schwarzer, D., Finking, R. \& Marahiel, M. A. (2003). Nonribosomal peptides: from genes to products. Nat Prod Rep 20, 275-287.

Schwyn, B. \& Neilands, J. B. (1987). Universal chemical assay for the detection and determination of siderophores. Anal Biochem 160, $47-56$.

Soengas, R. G., Anta, C., Espada, A., Paz, V., Ares, I. R., Balado, M., Rodriguez, J., Lemos, M. L. \& Jiménez, C. (2006). Structural characterization of vanchrobactin, a new catechol siderophore produced by the fish pathogen Vibrio anguillarum serotype $\mathrm{O} 2$. Tetrahedron Lett 47, 7113-7116.

Stojiljkovic, I., Baumler, A. J. \& Hantke, K. (1994). Fur regulon in Gram-negative bacteria. Identification and characterization of new iron-regulated Escherichia coli genes by a Fur titration assay. J Mol Biol 236, 531-545.

Stork, M., Di Lorenzo, M., Welch, T. J., Crosa, L. M. \& Crosa, J. H. (2002). Plasmid-mediated iron uptake and virulence in Vibrio anguillarum. Plasmid 48, 222-228.

Stork, M., Di Lorenzo, M., Welch, T. J. \& Crosa, J. H. (2007). Transcription termination within the iron transport-biosynthesis operon of Vibrio anguillarum requires an antisense RNA. J Bacteriol 189, 3479-3488.

Tabor, S. \& Richardson, C. C. (1985). A bacteriophage T7 RNA polymerase/promoter system for controlled exclusive expression of specific genes. Proc Natl Acad Sci U S A 82, 1074-1078.

Tolmasky, M. E. \& Crosa, J. H. (1991). Regulation of plasmidmediated iron transport and virulence in Vibrio anguillarum. Biol Met 4, 33-35.

Tolmasky, M. E., Actis, L. A. \& Crosa, J. H. (1993). A single amino acid change in AngR, a protein encoded by pJM1-like virulence plasmids, results in hyperproduction of anguibactin. Infect Immun 61, 3228-3233.

Tolmasky, M. E., Wertheimer, A. M., Actis, L. A. \& Crosa, J. H. (1994). Characterization of the Vibrio anguillarum fur gene: role in regulation of expression of the FatA outer membrane protein and catechols. $J$ Bacteriol 176, 213-220.

Toranzo, A. E. \& Barja, J. L. (1990). A review of the taxonomy and seroepizootiology of Vibrio anguillarum, with special reference to aquaculture in the northwest of Spain. Dis Aquat Organ 9, 73-82.

Touati, D. (2000). Iron and oxidative stress in bacteria. Arch Biochem Biophys 373, 1-6.

Vasil, M. L., Ochsner, U. A., Johnson, Z., Colmer, J. A. \& Hamood, A. N. (1998). The fur-regulated gene encoding the alternative sigma factor PvdS is required for iron-dependent expression of the LysRtype regulator ptxR in Pseudomonas aeruginosa. J Bacteriol 180, 6784-6788.

Wandersman, C. \& Delepelaire, P. (2004). Bacterial iron sources: from siderophores to hemophores. Annu Rev Microbiol 58, 611-647.

Wang, R. F. \& Kushner, S. R. (1991). Construction of versatile lowcopy-number vectors for cloning, sequencing and gene expression in Escherichia coli. Gene 100, 195-199.

Watnick, P. I., Butterton, J. R. \& Calderwood, S. B. (1998). The interaction of the Vibrio cholerae transcription factors, Fur and $\operatorname{IrgB}$, with the overlapping promoters of two virulence genes, $\operatorname{irg} A$ and $\operatorname{irg} B$. Gene 209, 65-70. 
Webster, A. C. \& Litwin, C. M. (2000). Cloning and characterization of $v u u A$, a gene encoding the Vibrio vulnificus ferric vulnibactin receptor. Infect Immun 68, 526-534.

Welch, T. J., Chai, S. \& Crosa, J. H. (2000). The overlapping $a n g B$ and ang $G$ genes are encoded within the trans-acting factor region of the virulence plasmid in Vibrio anguillarum: essential role in siderophore biosynthesis. J Bacteriol 182, 6762-6773.

Wertheimer, A. M., Verweij, W., Chen, Q., Crosa, L. M., Nagasawa, M., Tolmasky, M. E., Actis, L. A. \& Crosa, J. H. (1999). Characterization of the angR gene of Vibrio anguillarum: essential role in virulence. Infect Immun 67, 6496-6509.

Wolf, M. K. \& Crosa, J. H. (1986). Evidence for the role of a siderophore in promoting Vibrio anguillarum infections. J Gen Microbiol 132, 2949-2952.

Yanofsky, C. (2000). Transcription attenuation: once viewed as a novel regulatory strategy. J Bacteriol 182, 1-8.

Edited by: S. C. Andrews 